traumatic events is always an entirely negative experience and that post-traumatic stress disorder is the only post-traumatic mental illness.

I do not share the authors' reassurance that the three-year follow-up rate was only $48 \%$ as it provides ammunition for those who will, I fear, continue to provide psychological debriefing. Perhaps it is cynical to question their motives but I am troubled by the almost pornographic nature of human experiences outwith the normal. There is a voyeurism and the potential vicariously to become part of a traumatic event, even of history, by intervening. Society's or is it the media's cry is 'something must be done', and despite the growing body of evidence that psychological debriefing does not work, or is harmful, I suspect such work will not be halted unless society changes from its 'psychologicalisation' of human distress. There is an old military adage that applies here: 'the only thing harder than trying to get a new idea into a military mind is trying to get the old one out'.

Perhaps Mayou et al's paper reinforces the reality that there are no 'quick fixes' for human experiences. The provision of help should be directed towards those who are defined as affected by their experiences. Identifying these cases should be the challenge for psychiatry. Perhaps then the advice proffered by Salmon (1917) will be correctly applied, although such interventions are unlikely to be so simple.

Bisson, J. L., Jenkins, P. L., Alexander, J., et al (1997) Randomised controlled trial of psychological debriefing for victims of acute burn trauma. British Journal of Psychiatry, I7I, 78-8I.

Garb, R., Kutz, I., Bleich, A., et al (1987) Varieties of combat stress reaction: an immunological metaphor. British Journal of Psychiatry, I5I, 248-25I.

Kraus, R. P. (1997) Psychological debriefing for victims of acute burn trauma (letter). British Journal of Psychiatry, I7I, 583 .

Mayou, R. A., Ehlers, A. \& Hobbs, M. (2000)

Psychological debriefing for road traffic accident victims. Three-year follow-up of a randomised controlled trial. British Journal of Psychiatry, 176, 589-593.

Salmon, T.W. (1917) The care and treatment of menta diseases and war neuroses ('shell shock') in the British Army. Mental Hygiene, I, 509-547.

Turnbull, G., Busuttil, W. \& Pittman, S. (1997) Psychological debriefing for victims of acute burn trauma (letter). British journal of Psychiatry, I7I, 582.

I. Palmer Royal Defence Medical College, Fort Blockhouse, Gosport, Hampshire POI2 2AB

\section{Psychosocial treatment programmes for personality disorders: service developments and research}

Chiesa \& Fonagy (2000) clearly demonstrate the beneficial effects of therapeutic community treatment for personality disorder, and more so in the treatment limb with less hospitalisation and more day care.

The logical extension of this is to offer these programmes with only day care. Several units around the country are now doing this, including new units in Aberdeen and Maidstone, as well as long-established units such as our own in Reading and the Red House in Salford.

The evidence from systematic reviews and meta-analyses for the effectiveness of therapeutic communities in treatment of personality disorders is strong (Lees \& Manning, 1999) and, together with the Cassel study, demonstrates the need for new, creative ways of setting up effective treatment programmes.

A multi-centre research project funded by the National Lotteries Charities Board is now underway, which should help in this endeavour. It is using multi-level modelling and a path-analytic equation modelling technique to determine the impact of a number of features that therapeutic community programmes have. This research is more complex and sophisticated than a simple randomised controlled trial design, but for treatments that do not fit a drug model paradigm it will be much more helpful in designing effective programmes of therapy. The protocol is available at www.pettarchiv.org.uk/atc-protocol.htm.

Chiesa, M. \& Fonagy, P. (2000) Cassel Personality Disorder Study. Methodology and treatment effects. British Journal of Psychiatry, 176, 485-49I.

Lees, J. \& Manning, N. (1999) CRD Report 17: Therapeutic Community Effectiveness. A Systematic International Review of Therapeutic Community for People with Personality Disorders and Mentally Disordered Offenders. York: NHS Centre for Reviews and Dissemination, University of York.

R. Haigh West Berkshire Psychotherapy Service Winterbourne House, 53-55 Argyle Road, Reading RGI 7YL

\section{More disappointing treatment outcomes in late-life depression}

Tuma (2000) reported disappointing outcomes in the treatment of late-life depression. Suicide rates are highest in the elderly in many countries (Shah \& De, 1998), while treatment with drugs and electroconvulsive therapy consistently results in full recovery rates of less than 30\% (Murphy, 1983). Some studies show slightly more optimistic findings, such as Baldwin \& Jolley (1986) and Brodaty et al (1993) who demonstrated prognosis in later life approaching that in younger adults at one year. Yet others suggest that longer follow-up reveals a worse outcome (Forsell et al, 1994). These studies use standard physical treatments but make no mention of adjunctive psychological treatments of any kind.

There are still too few studies demonstrating the effects of psychological interventions in older people (O'Rourke \& Hadjistravropoulos, 1997). More recently published data have shown improved outcome using a combination of drug and psychological treatments, including interpersonal therapy and cognitive-behavioural therapy (Reynolds et al, 1999). In addition, important research by Ong et al (1987) demonstrated relapse prevention for individuals attending a support group.

In a recent postal survey, I enquired of members of the Royal College of Psychiatrists' Faculty for the Psychiatry of Old Age whether elderly patients in their care had specifically requested psychotherapy. The overall response rate was $65 \%$, of which $49 \%$ had experience of patients asking for psychotherapy. One can only assume that those already in receipt of such treatments would not ask for it. Patients rarely demand drug treatments as they are often already taking medication. The National Health Service (NHS) Executive (1996) review of psychotherapy services endorses the need for older patients to have access to similar service opportunities as the young.

Since elderly consumers of our service are asking for psychotherapy, and because there is some evidence (Roth \& Fonagy, 1996) that it is a useful adjuvant in the war against late-life depression, why are we still producing research which appears to ignore this approach?

Baldwin, R. C. \& Jolley, D. J. (1986) The prognosis of depression in old age. British Journal of Psychiatry, 149 574-583.

Brodaty, H., Harris, L., Peters, K., et al (1993) Prognosis of depression in the elderly. A comparison with younger patients. British Journal of Psychiatry, 163 589-596.

Forsell, Y., Jorm, A. F. \& Winblad, B. (1994) Outcome of depression in demented and non-demented elderly: Observations from a three-year follow-up in a 
community-based study. International Journal of Geriatric Psychiatry, 9, 5-10.

Murphy, E. (1983) The prognosis of depression in old age. British Journal of Psychiatry, 142, III-119.

NHS Executive (1996) NHS Psychotherapy Services in England: Review of Strategic Policy. London: Department of Health.

Ong, Y. L., Martineau, F., Lloyd, C., et al (1987) A support group for the depressed elderly. International Journal of Geriatric Psychiatry, 2, 119-123.

O'Rourke, N. \& Hadjistavropoulos, T. (1997) The relative efficacy of psychotherapy in the treatment of geriatric depression. Aging and Mental Health, I, 305-310.

Reynolds, C. F., Frank, E., Perel, J. M., et al (1999) Nortriptyline and IPT as maintenance therapies for recurrent major depression: a randomised controlled trial in patients older than 59 years. Journal of the American Medical Association, 281, 83-84.

Roth, A. D. \& Fonagy, P. (1996) What Works for Whom? A Critical Review of Psychotherapy Research New York: Guilford Press.

Shah, A. \& De, T. (1998) Suicide and the elderly, International Journal of Psychiatry Clinical Practice, 2, 3-17.

Tuma, T. A. (2000) Outcome of hospital-treated depression at 4.5 years. An elderly and a younger adult cohort compared. British Journal of Psychiatry, 176, 224-228.

S. I. Evans St Bartholomew's and Homerton Hospitals, London ECIY 7BE

\section{Medication and alcohol in nursing homes}

Furniss et al (2000) report the findings from a promising trial which addresses the inappropriate use of medication in nursing homes. They conclude that a pharmacist's review followed by a reduction in medication does not necessarily increase rates of morbidity or mortality. However, one commonly used drug that was not included in their review was alcohol.

Significant rates of alcohol misuse have been recorded in nursing home settings (Johnson, 2000), and interactions between prescribed (as well as over-the-counter) medication and alcohol pose significant risks for older people drinking unregulated amounts of alcohol. Alcohol interacts with many of the commonly prescribed medications cited in the study, especially antidepressants and sedatives. Therefore, residents in the study who drink alcohol will have benefited from the intervention of stopping medication by removing the risk of a potentially dangerous drug reaction.

As part of a survey in Bristol, I approached the managers of several residential homes to find out whether they held a policy regarding alcohol use in the home.
None of the seven homes surveyed had such a policy in place, despite some residents having alcohol problems, and it was not unusual for homes to sell alcohol on the premises, either across a bar or in a shop.

Pharmacists have a key role in advising patients of potential interactions with alcohol (Ward, 1997). The provision of clear and up-to-date information about these interactions could form part of an alcohol policy in nursing and residential homes.

Furniss, L., Burns, A., Craig, S. K. L., et al (2000) Effects of a pharmacist's medication review in nursing homes. Randomised controlled trial. British Journal of Psychiatry, I76, 563-567.

Johnson, I. (2000) Alcohol problems in old age: A review of recent epidemiological research. International Journal of Geriatric Psychiatry, in press.

Ward, M. (1997) Older People and Alcohol - A Neglected Area?, p. 63. London: Health Education Authority.

I. Johnson Cossham Hospital, Lodge Road, Kingswood, Bristol BSI5 ILF

\section{Talmudic, Koranic and other classic reports of stalking}

Kamphuis \& Emmelkamp's (2000) review on stalking gives an acute clinical perspective to the Hebrew myth of Joseph and Zuleika related in Genesis XXXIX. After being sold as a slave, Joseph became the target of his master's wife's wanton passion. $\mathrm{He}$ steadfastly rejected all her amorous advances and was eventually condemned to prison on account of her calumnies.

This archetype of stalking has many derivations in Jewish, Arabic, Syriac, Persian, Indian and medieval European lore (Rappoport, 1995). Talmudic and midrashic accounts emphasise the complex behavioural sequence of the stalker: implicit seductive manoeuvres; explicit proposals; verbal menaces; planned physical aggression; false accusations; humiliation and punishment.

Moslem tradition, based on Mohammed's twelfth sura, elaborates on the erotomanic aspects of the myth. Yusuf was also in love with Zulaikha, but had no hope of reciprocity. When Yusuf had been freed from prison and appointed in the place of his former master, he married his widowed former mistress and stalker (Weil, 1845). Islamic comments also acknowledge Zulaikha's love as her only excuse. This theme of the stalkee's irresistible charm, already explicit in the Koran, is refined by Persian poets such as Firdusi (933-1025) and especially Jami (1414-1492), whose powerful metaphor of the 'fair gazelle' applied to Yusuf conveys the ambivalence of feminine grace and quick escape (Jami, 1882). Ephrem Syrus addresses the stalker's distorted insight: "Out of love for him, I treated him unjustly; and yet he owes his present greatness to us" (Grünbaum, 1901).

Christian authors tend to draw a parallel between Joseph and the Saviour. Emphasis is therefore placed on forgiveness by the stalkee. The stalker's insight is finely verbalised in 14th-century passion plays: "Principallement une dame / Comme moy; je suis esbahye / Je considère ma follye / Mais, bref, amour me contrainct tant / Qu'il sera force que je prie / Joseph pour estre mon amant" (Anonymous, 1881). In 16th-century Yiddish dramas composed for Purim, a festival celebrating the liberation of Jews from a deadly plot, the slave's and the mistress's alienation and freedom are dialectically discussed and Joseph's stalker goes by many different names (but not Zuleika). Zuleika's syndrome is also staged with other nuances by Goethe and in a famous Broadway show. This overview reinforces Kamphuis \& Emmelkamp's view of a typical phenomenon which has remained a contemporary challenge, and also their suggestion of cultural biases in the perception of stalking.

Anonymous (188I) Le Mistère du Vieil Testament (ed. J. de Rothschild), Tome III, pp. 67-69. Paris.

Grünbaum, G. (1901) Gesammelte Aufsätze zur Sprache und Sagenkunde. Berlin.

Jami, M. N. (1882) Yusuf and Zuliaykha (trans. R. T. H. Griffith). In Oriental Series. London: Trübner.

Kamphuis, J. H. \& Emmelkamp, P. M. G. (2000)

Stalking - a contemporary challenge for forensic and clinical psychiatry. British Journal of Psychiatry, 176, 206-209.

Rappoport, A. S. (1995) Ancient Israel. Volume Two. London: Studio Editions.

Weil, G. (1845) Biblische Legenden der Muselmänner. Frankfurt am Main.

B. Dan Neurology Department, University Children's Hospital Queen Fabiola, 15 Avenue J J Crocq, B-1020 Brussels, Belgium

C. Kornreich Institute of Psychiatry, Brugmann University Hospital, Université Libre de Bruxelles, B-1020, Belgium

\section{Venlafaxine-induced painful ejaculation}

Antidepressant drugs cause a variety of sexual side-effects. Painful ejaculation is a 